\title{
KNOWLEDGE ON SELF- MEDICATION AND ITS HEALTH IMPACTS AMONG ADULTS
}

\author{
Santhi. $\mathbf{P}^{1}$, Santhiya. $\mathbf{C}^{2}$, Saranya. $\mathbf{R}^{2}$, Shamili. $\mathbf{R}^{2}$, Sindhuja. $\mathbf{P}^{2}$, \\ Sivagami. $V^{2}$, Sivarajkumar. $R^{2} \&$ Sneka. $N^{2}$ \\ ${ }^{I}$ Associate Professor \& Research Guide, Vinayaka Mission's College of Nursing, Karaikal, \\ Vinayaka Mission's Research Foundation (DU), Salem. \\ ${ }^{2}$ B.Sc.(N) Final Year students, Vinayaka Mission's College of Nursing, Karaikal, Vinayaka \\ Mission's Research Foundation (DU), Salem.
}

Author for Correspondence: Mrs. P. Santhi,

\begin{abstract}
Today's is very different from that of the past years with many inventions. Many things are inverted that make a lot of people to live in luxury. But along with these, in term of the health of the people nowadays, there are certain diseases that are quite making a name in the statistical data of health department. People are now suffering from the certain diseases throughout the world and many are practicing self medication to relieve symptoms of their health problems. The present study aimed to assess the knowledge on self medication and its health impacts among adults. Methodology: The Research Design adopted for the present study was nonexperimental descriptive design. This study was carried out in selected rural area Serumavilangai, Karaikal District. A total of 100 adults between 18-45 years of age were selected by using Purposive sampling technique for the present study. Self structured interview schedule was used to collect data from each participant. Result: The finding of present study showed that the maximum $68 \%$ of adults had moderate knowledge on self medication and its impact, 29\% of adults had inadequate knowledge and only $3 \%$ of adults had adequate knowledge on the self medication and its health impacts. The results indicated that there is a greater need to impart knowledge on ill effects of self medication to the public in order to reduce its health impacts. Conclusions: The present study concluded that educating with multiple audiovisual aids is required to arouse awareness among adults on ill effects of self medication on their health and to prevent development of complications like renal diseases, metabolic disorders, addition of drugs, anxiety, stress, etc.
\end{abstract}

KEY WORDS: Assess, Knowledge, Self Medication, Health Impacts, Adult

\section{INTRODUCTION}

Generation today is very different from that of the past years. Many things are inverted that make a lot of people to live in luxury. But along with these, in term of the health of the people nowadays, there are certain diseases that are quite making a name in the statistical data of health department. People are now suffering from the certain diseases like diabetes, hypertension, asthma, renal disorders, cirrhosis of liver, gastritis, ulcer, GERD, vomiting, diarrhoea, fever, common cold and many other due to sedentary lifestyle, stress and unhygienic measures, food pattern, lack of healthy activities, exercise etc... Every day, throughout the world, many are practicing 


\section{SJIF Impact Factor 2021: 8.013| ISI I.F.Value:1.241| Journal DOI: 10.36713/epra2016 ISSN: 2455-7838(Online) EPRA International Journal of Research and Development (IJRD)}

self medication to relieve symptoms of their health problems. The most widely self medicated substances are over the counter drugs used to treat common health issues at home, as well as dietary supplements. These do not require a doctor's prescription to uptime and in some countries are available in supermarkets and convenience stores. Self-medication involves acquiring medicines without a prescription, resubmitting old prescriptions to purchase medicines to treat similar or same problem at present, sharing medicines with relatives or members of one's social circle or using leftover medicines stored at home. It is commonly prevailing in developing countries like India due to easy availability of wide range of drugs coupled with inadequate health services result in increased proportion of drugs used as self medication. It can lead to irrational use of drugs, wastage of resources, and increased resistance of pathogens in addition to serious health hazards such as adverse drug reaction and prolonged morbidity. Economic, political, and cultural factors have stimulated a constant increase in self-medication worldwide, turning this practice into a major public health problem.

\section{Statement}

A study to assess the knowledge on self medication and its health impacts among adults in selected rural area, Karaikal

\section{Objectives}

$>$ To assess the knowledge on self medication and its health impacts among adults in selected rural area.

$>$ To associate level of knowledge with selected demographic variables of adults.

\section{RESEARCH METHODOLOGY}

The Research Design adopted for the present study was nonexperimental descriptive design. This study was carried out in selected rural area Serumavilangai, Karaikal District. A total of 100 adults between $18-45$ years of age were selected by using Purposive sampling technique for the present study. Self structured interview schedule was used to collect data from each participant. Tools were developed by the investigator based on literature review and experts opinion. It consisted of two parts. Section A consisted of 10 items related to demographic variables of adults such as age in years, sex, educational status, occupation, monthly family income, religion, marital status, Presence of associated medical condition, previous history of self medication \& Source of information obtained on ill effects of self medication. Section B of the tool consisted of 25 items related to knowledge on Self-
Medication and its Health Impacts. It included the questions on meaning, reasons for self medication, benefits, disadvantage, common drugs used for self medication, impact of self medication on health and its prevention. After self introduction, the investigator explained the purpose of the study to the samples. The confidentiality of their responses was assured and their written consent was taken prior to the study. The self structured interview schedule was administered to each adult who met the inclusive criteria. It took about 15-20 minutes to collect information from each adult. Every day the data was collected from 8-10 study participants. The descriptive statistical tests percentage, mean and standard deviation were used for assessing knowledge level and Chi-square test was used to find out the association between the demographic variables of adults with their knowledge on self medication and its health impacts.

\section{RESULTS}

The major findings of the study revealed that regarding the age of the study participants, the majority of adults $26(26 \%)$ were between the age group 41-45 years and only $16(16 \%)$ adults were between the age group of $36-40$ years. Greater number of study participants $58(58 \%)$ were males and lesser number of adults $42(42 \%)$ were females. The higher percentage of adults $36 \%$ (36) had primary education and only $5(5 \%)$ were illiterate. The maximum number of adults $55(55 \%)$ were working in private concerns and only one $(1 \%)$ were working as a government employee and another only one $(1 \%)$ were self employed and doing business. The majority 33 (33\%) had above Rs.15,000/- as monthly family income and only 4 (4\%) had between Rs.10,000/- to Rs.15,000/- . The higher number of adults $59(59 \%)$ were belonged to Hindu religion, 25 (25\%) were belonged to Christianity and $16(16 \%)$ were belonged Muslims. The greater number of adults $58(58 \%)$ were married and the less number of adults 42 (42\%) were unmarried. Regarding the source of getting information on self medication and its impact on health, most of the adults $46(46 \%)$ were obtaining information from Health care professionals and only $13(13 \%)$ were getting from Peer groups.

The results of the present study revealed that the majority of adults $68 \%$ (68) had moderate knowledge, 29\% (29) had inadequate knowledge and only $3 \%$ (3) had adequate knowledge on self medication and its health impacts. The result of the present study revealed that there was a significant association between level of knowledge on self medication \& its health impact only with demographic variables, age $\left(\square^{2}=13.529\right)$ and 
occupation ( $\left.\square^{2}=68.8515\right)$ of adults and there was no significant association between level of knowledge with the other demographic variables such as sex, educational status, religion, monthly family income, marital status, presence of associated medical conditions, previous history of self medication and source of obtaining information.

\section{DISCUSSION}

The result of the present study revealed that the majority of adults $68 \%$ (68) had moderate knowledge, 29\% (29) had inadequate knowledge and only $3 \%$ (3) had adequate knowledge on self medication and its health impacts. This was similar to the results of a study to determine the perception and level of awareness regarding OTC medications, among the general public in Malaysia conducted by Mohamed Irfadh Mohamed Azhar et al (2020) which revealed that about $82 \%$ of the respondents stated that their level of knowledge regarding OTC medications was moderate to low. The result of various studies also reported that the source of drug information was past experience with drugs, followed by relatives/ friends, pharmacists, advertisements, internet, etc.

The result of the present study revealed that there was a significant association between level of knowledge on self medication \& its health impact with demographic variables age and occupation of adults. This was correspondence with the findings of the study conducted by Atmadani, R.N., Nkoka, O., Yunita, S.L. et al. (2020) on Self-medication and knowledge among pregnant women attending primary healthcare services in Malang, Indonesia reported that the knowledge on self medication was low in younger age, illiterate, with less education, low income status and unemployed when compared to older people, high education and having occupation. Additionally the result of the present study was also supported by the study conducted by Selvaraj K., Kumar S. G., \& Ramalingam A. (2014) on prevalence of self-medication practices and its associated factors showed that sex, occupation and age factors of the subjects were found to be associated with self-medication. Males aged $>40$ years and involving in moderate level activity of occupation, were found to be significantly associated with higher self-medication usage. This revealed that the age, educational status and occupational status influence the knowledge and self medication practices of the adults.

\section{CONCLUSION}

The result of the present study revealed that 29\% (29) had inadequate knowledge. Most adults commonly used to take self medication for minor illnesses or for chronic illnesses due to ignorance and carelessness. Self medications either for a shorter or longer duration can produce major impact on physical and psychological conditions of human beings. The present study concluded that educating with multiple audiovisual aids is required to arouse awareness among adults on ill effects of self medication on their health and to prevent development of complications like renal diseases, metabolic disorders, addition of drugs, anxiety, stress, etc.

\section{Recommentations}

The present study recommends the following:

- A similar study can be conducted in different settings with large samples.

- A comparative study can be conducted among adults living in rural and urban areas

- A study to assess the pattern and determinants of self medication among adults can be carried out.

- A similar study can be conducted to find the physical, psychosocial impacts of self medication among adults.

- A Planned teaching programme of prevention of self medication and its health impacts can be carried out among adults in rural areas. 


\section{FIGURES}

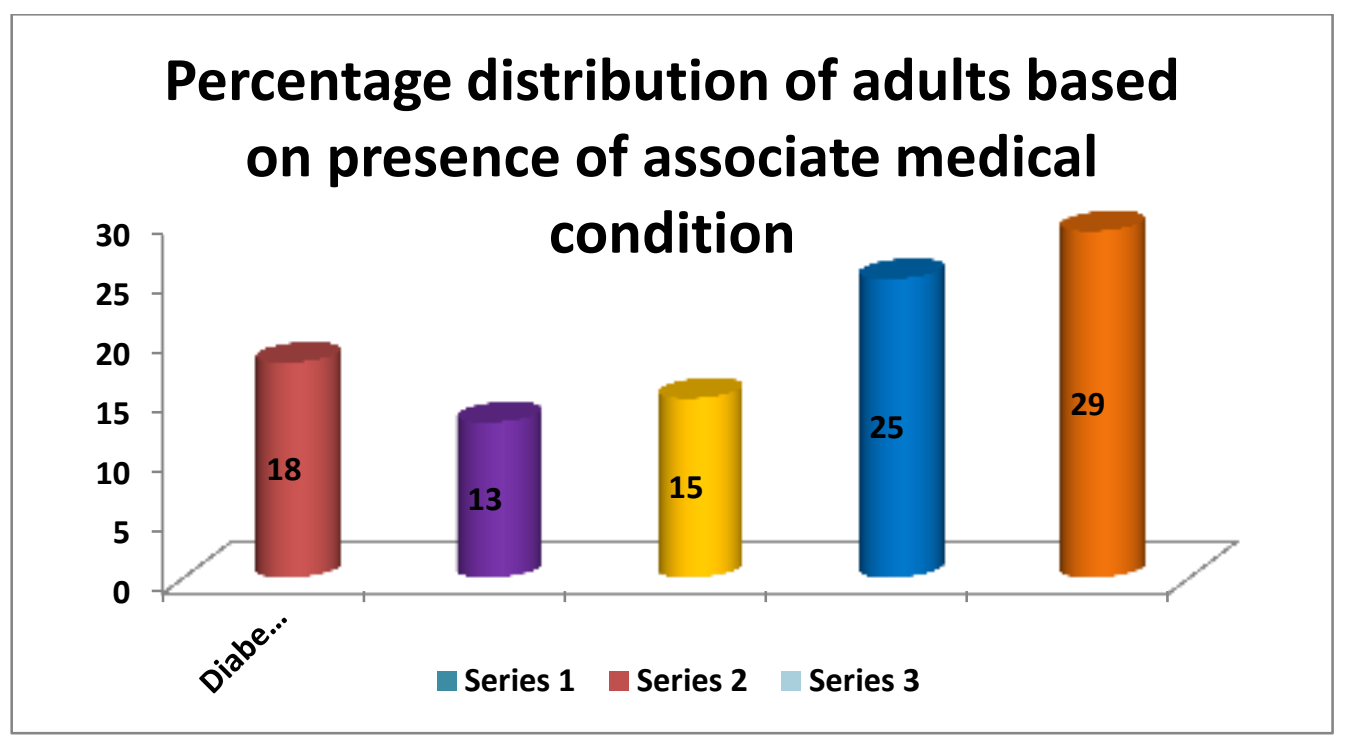

Fig. 1: Distribution of adults based on Presence of Associate Medical Condition

\section{Distribution of adults based on previous history of self medication}

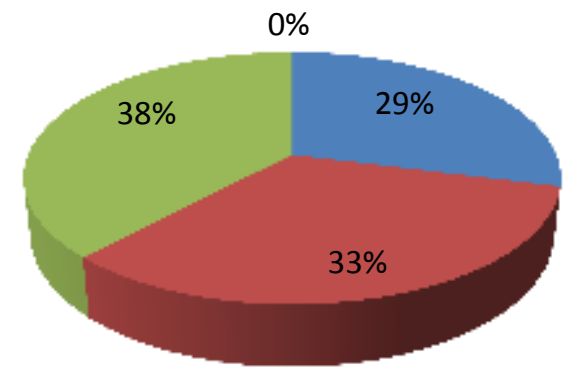

Often

- Sometimes

Never

Fig. 2: Distribution of adults according to the Previous History of Self Medication

\section{REFERENCES}

1. Jain M, Prakash R, Bapna D, Jain R. (2015). Prevalence and Pattern of Self medication Practices in Urban area of Southern Rajasthan. Ntl J of Community Med 2015; 6(4):474-477.

2. Kumar V, Mangal A, Yadav G, Raut D, Singh S. (2015). Prevalence and pattern of selfmedication practices in an urban area of Delhi, India. Med J DY Patil Univ 2015;8:16-20

3. Selvaraj, K., Kumar, S. G., \& Ramalingam, A. (2014). Prevalence of self-medication practices and its associated factors in Urban Puducherry, India. Perspectives in clinical research, 5(1), 3236.
4. Hajira Saba I., Shivananda K. S., Mini Jayan, C. Althaf Hussain. (2016). Prevalence of selfmedication practices and its associated factors in rural Bengaluru, Karnataka, India. Int $J$ Community Med Public Health. 2016 Jun;3(6):1481-1486

5. Balamurugan $E$ and Ganesh K. (2011). Prevalence and Pattern of Self Medication use in coastal regions of South India. British Journal of Medical Practitioners. 4(3):a428

6. Rajendran A, Kulirankal KG, Rakesh $P S$, George S. (2019). Prevalence and pattern of antibiotic self-medication practice in an urban population of Kerala, India: A cross-sectional 
study. Indian J Community Med.44, Suppl S1:425

7. Patrick S, Badyal D. (2018). Self-medication practices in patients attending a Tertiary Care Teaching Hospital in Urban North-West India. Acta Med Int 2018;5:44-7

8. Manish Jai, Rahul Prakash, Dhriti Bapna \& Rohit Jain (2015). Prevalence and Pattern of Self-Medication Practices in Urban Area of Southern Rajasthan. National Journal of Community Medicine. Oct-Dec. 6(4): 474-477

9. Kiranbir Chouhan \& Dr. Shyam Baboo Prasad. (2016). Self-medication and their consequences: A challenge to health professional. Asian Journal of Pharmaceutical and Clinical Research. 9(2):314-317

10. Kumar N, Kanchan T, Unnikrishnan B, Rekha T, Mithra P, Kulkarni V, Papanna MK, Holla R, Uppal S. (2013). Perceptions and practices of self-medication among medical students in coastal South India. PLoS One. 2013 Aug 28;8(8):e72247.

11. Maria Ayub et al. (2015). Prevalence And Consequences Associated With Self Medication In Our Society: A global issue. International Research Journal of Pharmacy 6(8):548-551

12. Alamgir K, Salahuddin K, Syed A A, Manzoor K.(2018). Health Complications Associated with Self-Medication. J Phy Fit Treatment \& Sports. 2018; 1(4): 555566.

13. Sridhar, S. B., Shariff, A., Dallah, L., Anas, D., Ayman, M., \& Rao, P. G. (2018). Assessment of Nature, Reasons, and Consequences of Selfmedication Practice among General Population of Ras Al-Khaimah, UAE. International journal of applied \& basic medical research, 8(1), 3-8.

14. Jember, E., Feleke, A., Debie, A., \& Asrade, G. (2019). Self-medication practices and associated factors among households at Gondar town, Northwest Ethiopia: a cross-sectional study. BMC research notes, 12(1), 153.

15. Dessalegn Asmelashe Gelayee, (2017). SelfMedication Pattern among Social Science University Students in Northwest Ethiopia. Journal of Pharmaceutics, vol. 2017. 5 pages.

16. Ravishankar. P, Arun Dubey Neelam Dwivedi \& Atanu Nandy. (2016).Knowledge, attitude and practice of self-medication among premedical and basic science undergraduate medical students. Asian Journal of Medical Sciences. 7.(6): 63-68

17. Mgbahurike A. A., \& Nenwi G. F. (2020). Prevalence, Knowledge, Practice and Perception of Self Medication among Pharmacy Students in a Nigerian tertiary Institution. Journal of Medical Biomedical and Applied Sciences, 8(8), 494-503.

18. Mohamed Irfadh Mohamed Azhar, Kabisha Gunasekaran, Amudha Kadirvelu, Sunil Gurtu, Sivalal Sadasivan, Bharti Madanlal Kshatriya. (2020). Self-medication: Awareness and Attitude among Malaysian Urban Population. International Journal of Collaborative Research on Internal Medicine \& Public Health. Vol. 5 No. 6: $436-443$

19. Atmadani, R.N., Nkoka, O., Yunita, S.L. et al. (2020). Self-medication and knowledge among pregnant women attending primary healthcare services in Malang, Indonesia: a cross-sectional study. BMC Pregnancy Childbirth 20, 42 (2020).

20. Sayed MA, Khadije J, Khirollah S, Alireza A, Mansour PV. (2016). The prevalence and affecting factors on self-medication J Clinical and Diagnostic Research. 2016: 10(5).

21. Lukovic JA, Miletic V, Pekmezovic T, Trajkovic G, Ratkcovic N, Aleksic D,Grgurevic A. (2014). Self-medication practices and risk factors for self-medicationamong medical students in Belgrade, Serbia. PLoS One. 2014;9(12):e114644.

22. Johnson D, Sekhar HS, Alex T, Kumaraswamy $M$, Chopra RS. Self medication practice among medical, pharmacy and nursing students. Int $J$ Pharm Pharm Sci. 2016;8(7). ISSN-0975-1491.

23. Ayalew MB. (2017). Self-medication practice in Ethiopia: a systematic review. Patient preference and adherence. 2017;11:401

24. Helal. R.M and H.S. Abou-Elwafa. (2017). Selfmedication in University students from the city of Mansoura, Egypt. Available from https://doi.org/10.1155/2017/9145193.

25. Roberts, J.T.F. (2020). How to Regulate the Right to Self-Medicate. HEC Forum (2020). Available from https://doi.org/10.1007/s10730020-09415-7

26. World Health Organization (WHO) guidelines for the regulatory assessment of Medicinal Products for use in self-medication. Available from: http://www.apps.who.int/medicinedocs/en/d/Js

27. Anthony Ike Wegbom, Clement Kevin Edet, Olatunde Raimi et al. (2020). Self-medication practices and associated factors in the prevention and/or treatment of COVID-19 virus: A population-based survey in Nigeria. Available at Research Square https://doi.org/10.21203/rs.3.rs-91101/v1 